\title{
PENGARUH PEMBERIAN TERAPI DZIKIR DALAM MENURUNKAN NYERI PADA PASIEN POST OPERASI
}

\author{
Yorpina $^{1}$, Ani Syafriati ${ }^{2}$ \\ Program Studi Sarjana Keperwatan STIKES Mitra Adiguna Palembang \\ Komplek Kenten Permai Blok J No 9-12 Bukit Sangkal Palembang 30114 \\ Email: yorpiana.1412@gmail.com
}

\begin{abstract}
Abstrak
Nyeri termasuk dalam pengalaman sensorik dan emosional yang sangat tidak menyenangkan dipicu oleh suatu stimulus pada ujung saraf sensorik. Semua pasien akan merasakan nyeri apabila efek anastesi sudah hilang, karena obat-obatan analgesic yang diberikan pasca operasi bertahan selama 6-8 jam. Tujuan penelitian ini untuk menganalisa pengaruh terapi dzikir dalam menurun nyeri pada pasien post operasi. Metode penelitan ini mengunakan desain pra-experimental dengan pendekatan (one group pre post test design). Jumlah sampel 38 responden dengan tehnik accidental sampling. Yang diberikan intervensi terapi dzikir. Data dikumpulkan dengan lembar obsevasi dan instrumen penelitian menggunakan mp3 mendengarkan dzikir. Hasil uji statistik dengan Wilcoxon dapat diungkapkan bahwa terdapat pengaruh pemberian terapi dzikir dalam menurukan nyeri pada pasien post operasi dengan hasil p value adalah 0,000. Ada pengaruh terapi dzikir dalam menurunkan nyeri pada pasien post opersi. Diharapkan pelayanan keperawatan agar melakukan terapi dzikir tersebut dan harapakan kepada pasien dapat melalukan terapi tersebut untuk menurunkan nyeri secara mandiri.
\end{abstract}

Kata kunci: Nyeri, Post operasi, Dzikir, skala nyeri.

\begin{abstract}
Pain is includes sensory and emotional experience that are very unpleasant that trigerred by a stimulus at the sensory nerve endings. All of the patiens will feel pain when the anesthetic effect is gone, because of the analgesic drugs given after surgery last for 6-8 hours. The purpose of this study aims to analyze the effect of remembrance therapy in reducing pain in postoperative patients. This research method uses a pra-experimental design with an approach (one group pre post test design). the number of samples 38 respondents with accidental sampling techniques. given therapeutic intervention dzikir. Data were collected by observation sheets and MP3 research instruments using remembrance therapy. The results of statistical test with Wilcoxon can be revealed that there is an effect of giving dzikir therapy in reducing pain in postoperative patients with a $p$ value of 0,000. There is an effect of dzikir therapy in reducing pain in postoperative patients. nursing services are expected to perform the dzikir therapy and it is expected that patients can carry out these therapies to reduce pain independently.
\end{abstract}

Keywords: Post Operativ, Pain, Dzikir, Pain Scale. 


\section{PENDAHULUAN}

Tindakan pembedahan merupakan ancaman potensial maupun aktual terhadap integritas seseorang yang dapat membangkitkan reaksi stres, fisiologi maupun psikologis. Himpunan perawat kamar bedah indonesia (HIPKABI) mendefinisikan tindakan operasi sebagai prosedur medis yang bersifat invasif dan diagnosis, pengobatan penyakit, trauma, dan deformitas (HIPKABI, 2014), Pembedahan adalah semua tindakan pengobatan yang menggunakan cara invasif dengan membuka atau menampilkan bagian tubuh yang akan ditangani (Redho dkk, 2019).

Data yang diperoleh dari The World Bank, tindakan operasi bedah didunia hingga tahun 2015 sebanyak 4.511 .101 per 100.000 populasi dengan posisi tertinggi yaitu benua australia sebanyak 28.907 per 100.000 populasi (Barus dkk, 2018). Berdasarkan data diperoleh dari World Health Organization (WHO), jumlah pasien dengan tindakan operasi mencapai angka peningkatan yang signifikan mencapai 140 juta pasien pada tahun 2011 di seluruh rumah sakit dunia, sedangkan pada tahun 2012 mengalami peningkatan 148 juta pasien. Di Indonesia pada tahun 2012 mencapai 1,2 juta pasien. Tindakan operasi menempati urutan ke 11 dari 50 pertama penanganan pola penyakit dirumah sakit se-Indonesia (Kemenkes RI, 2013 dalam Yadi 2018.

Berdasarkan data rekam medis khususnya dirungan operasi Rumah Sakit TK II Dr. AK Gani Palembang tahun 2017 jumlah pasien yang melakukan tindakan pembedahan di rungan operasi sebanyak 4.990 pasien, pada tahun 2018 sebanyak 3.834 pasien, dan pada tahun 2019 sebanyak 3.762 pasien.

Masalah yang timbul setelah tindakan operasi adalah nyeri. Nyeri pasca bedah mungkin sekali disebabkan oleh luka operasi, tetapi bisa juga disebabkan yang lain. Proses timbulnya keluhan nyeri dari rangsang nosisepi yang disebabkan noksa, setelah itu penderita menyadari adanya noksa, baru kemudian mengalami sensasi nyeri dan akhirnya timbul reaksi terhadap nyeri dalam bentuk sikap dan prilaku verbal maupun nonverbal dalam menyampaikan apa yang dirasakannya (Redho dkk, 2019).

Nyeri adalah pengalaman emosional yang tidak menyenangkan berkaitan dengan kerusakan jaringan yang aktual, potensial, atau yang dirasakan dalam kejadian-kejadian saat terjadi kerusakan. Nyeri dapat diartikan sebagai suatu sensasi yang tidak menyenangkan baik secara sensori maupun emosional yang berhubungan dengan adanya suatu kerusakan jaringan atau faktor lain, sehingga individu merasa tersiksa, menderita yang akhirnya akan menganggu aktivitas sehari-hari (Asmadi, 2009). Nyeri termasuk dalam pengalaman sensorik dan emosional yang sangat tidak menyenangkan dipicu oleh suatu stimulus pada ujung saraf sensorik. Semua pasien akan merasakan nyeri apabila efek anastesi sudah hilang, karena obat-obatan analgesic yang diberikan pasca operasi bertahan selama 6-8 jam (Smaltzer, 2010 dalam Rochmawati, 2018).

Penatalaksanaan nyeri pasca bedah untuk mengurangi atau menghilangkan nyeri pasca bedah dilakukan dengan pendekatan farmakologi dan non farmakologi salah satu penatalaksanaan farmakologis adalah Astaminopen Nonsteroidal Anti-Inflammatory Medications (NSAID), secara garis besar srategi farmakologi dalam pemberian terapi mengikuti WHO pain relief ladder (jenjang analgetik), adapun contoh obatnya ketorolac ibuprofen, aspirin dll. sedangkan penatalaksanaan non farmakologi adalah dengan pemberian kompres panas dan dingin, masase, distraksi mendengarkan, tehnik relaksasi nafas dalam dan tehnik terapi dzikir. Salah satu terapi yang diberikan oleh peneliti adalah terapi dzikir.

Terapi dzikir adalah jenis terapi ritme yang teratur disertai sikap pasrah pada objek transendensi yaitu Allah. Frase yang digunakan dapat berupa nama-nama Allah, atau kata yang memiliki makna menenangkan sehingga mampu mengurangi rasa nyeri (Himawan dkk, 2017). Dzikir merupakan rangkaian kalimat yang diucapkan untuk 
mengingat Allah, setiap manusia sebagai hamba Allah yang berakal sehat hendaknya selalu mengingat Allah dalam keadaan senang maupun sedih dan sehat maupun sakit. Dzikrullah hendaknya dilakukan dengan hati yang penuh keikhlasan sehingga dapat menunjukkan bahwa dirinya mendapat bimbingan dari Allah SWT (Mathroni, 2009)

Berdasarkan hasil studi pendahuluan di Rumah Sakit TK II Dr AK Gani Palembang didapatkan hasil pasien yang melakukan tindakan pembedahan pada bulan agustus mencapai 176 pasien, bulan september mencapai 157 pasien dan pada bulan oktober 2019 mencapai 132 pasien. Hasil wawancara dengan perawat untuk penanganan nyeri adalah dengan pemberian farmakologi dan secara non farmakologi menggunakan tehnik relaksasi nafas dalam, kompres hangat dan dingin. Namun jarang dilakukan, dikarnakan lebih mengutamakan teknik farmakologi dalam pemberian anti nyeri, dan belum ada yang menerapkan tehnik distraksi mendengarkan dzikir. Hasil observasi dan wawancara pada semua pasien yang operasi, pasien mengatakan selain obat untuk mengatasi nyeri belum ada tindakan lain. Tehnik distraksi mendengarkan dzikir digunakan sebagai terapi pendamping farmakologi. Alasan memilih terapi zikir karena selain berfungsi sebagai salah satu manajemen nyeri non farmakologi, dzikir juga berfungsi memenuhi kebutuhan pasien selain itu dzikir juga dapat menenangkan diri dan dapat membersihkan dari perilaku dan akhlak buruk.

Tugas seorang perawat adalah membantu memenuhi kebutuhan secara biopsiko-spiritual. Salah satunya yaitu dalam pemberian intervensi keperawatan menggunakan tehnik non farmakologi untuk menurunkan nyeri. Tujuanya agar pasien dapat melakukan pengobatan secara mandiri dan mengurangi beban kerja ginjal dalam toksik obat-obatan.

Berdasarkan uraian diatas, salah satu untuk cara mengurangi rasa nyeri memberikan terapi non farmakologi yaitu dengan terapi dzikir, nyeri memberikan dampak negatif sehingga harus ditangani, metode dzikir memiliki banyak manfaat seperti memberikan ketenangan, dan berserah diri. Sehingga peneliti ingin meneliti apakah dzikir mampu menurunkan nyeri pasca operasi.

\section{METODE PENELITIAN Jenis Penelitian}

Jenis penelitian ini menggunakan desain pra-experimental dengan pendekatan (One Group Pre Post Test Design). Dimana dalam peneltian ini sampel diberikan pretest (pengamatan awal) terlebih dahulu sebelum diberikan intervensi, setelah itu diberikan intervensi, kemudian dilakukan posttest (pengamatan akhir).

\section{Waktu dan Tempat Penelitian}

Penelitian ini dilaksanakan selama kurang lebih 1 (satu) bulan. Dari tanggal 15 Maret 2020 -15 April 2020. Penelitian ini dilakukan di Ruangan Bedah Rumah Sakit TK II Dr. AK Gani Palembang.

\section{Target /Subjek Penelitian}

Metode penelitan ini mengunakan desain pra-experimental dengan pendekatan (one group pre post test design). Jumlah sampel 38 responden dengan tehnik accidental sampling. Yang diberikan intervensi terapi dzikir. Data dikumpulkan dengan lembar obsevasi dan instrumen penelitian menggunakan mp3 mendengarkan dzikir.

\section{Prosedur}

Jenis penelitian ini pre-eksperimen dengan menggunakan rancangan (one group pre post test design).

Penelitian ini dimulai dari pengajuan izin penelitian dari STIKES Mitra Adiguna Palembang, kemudian ditujukan ke Rumah Sakit TK II Dr. AK Gani. Selanjutnya dilakukan studi pendahuluan dan observasi lapangan. Menentukan responden dengan tehnik accidental sampling, selanjutnya dilakukan penjelasan tujuan dan prosedur penelitian, (informed consent) kemudian pada tahap pelaksanaan penelitian, pasien post 
operasi dilakukan pengukuran skala nyeri dengan menggunakan scala numeric, selanjutnya peneliti memberikan intervensi terapi audio dzikir. Setelah itu, dilakukan pengukuran skala nyeri kembali setelah mendengarkan dzikir. Kemudian data dianalisis menggunakan SPSS.

Data, Instrumen, dan Tehnik Pengumpulan data

Penelitian ini menggunakan instrument lembar observasi pre dan post test pemberian terapi audio dzikir. Data dimasukan dalam tabel dan pengolahan data dilakukan melalui analisa statistik dengan menggunakan komputer.

\section{Tehnik Analisa Data}

Analisa univariat dilakukan terhadap variabel dependen (nyeri post operasi) dianalisa dengan menggunakan tabel distribusi frekuensi (shapiro wilk)

Analisa bivariat dilakukan terhadap variabel independent (terapi audio dzikir) dilakukan terlebih dahulu uji normalitas data menggunaka uji non parametrik test yaitu uji Wilcoxon. Dengan ketentuan p value $<(0,05)$ berarti data tidak berdistribusi normal. Jika $p$ value > $(0,05)$ berarti data berrdistribusi normal.

Dalam melakukan penelitian, peneliti memperhatikan masalah-masalah etika penelitian, yang meliputi: informend consent, anonimity, Self determination, pripacy, Protection from discomfort.

\section{HASIL DAN PEMBAHASAN}

Analisa Univariat

Tabel 1. Distribusi frekuensi karakteristik tingkat nyeri pre dan post test

\begin{tabular}{cccccc}
\hline $\begin{array}{c}\text { N } \\
\text { o }\end{array}$ & $\begin{array}{c}\text { Vari } \\
\text { abel }\end{array}$ & $\begin{array}{c}\text { Pre- } \\
\text { test }\end{array}$ & \multicolumn{3}{c}{$\begin{array}{c}\text { Post- } \\
\text { test }\end{array}$} \\
\cline { 3 - 6 } & & $\begin{array}{c}\text { Freku } \\
\text { ensi }\end{array}$ & $\begin{array}{c}\text { Perse } \\
\text { ntase }\end{array}$ & $\begin{array}{c}\text { Freku } \\
\text { ensi }\end{array}$ & $\begin{array}{c}\text { Perse } \\
\text { ntase }\end{array}$ \\
\hline 1 & $\begin{array}{l}\text { Tidak } \\
\text { nyeri }\end{array}$ & 0 & 0 & 0 & 0 \\
\hline 2 & & & & \\
\hline & $\begin{array}{l}\text { Nyeri } \\
\text { ringan }\end{array}$ & 0 & 0 & 12 & 31, \\
\hline 3 & $\begin{array}{l}\text { Nyeri } \\
\text { sedang }\end{array}$ & 32 & 84,2 & 22 & 57 \\
& & $\%$ & & $9 \%$ \\
\hline
\end{tabular}

\begin{tabular}{llcccc}
\hline 4 & $\begin{array}{l}\text { Nyeri } \\
\text { berat }\end{array}$ & 6 & $\begin{array}{c}15.8 \\
\%\end{array}$ & 4 & 10, \\
\hline 5 Nyeri & 0 & 0 & 0 & 0 \\
& berat & & & & \\
& tidak & & & & \\
& terkontr & & & & \\
& ol & & & & \\
\hline
\end{tabular}

Sumber data primer , 2020

Berdasarkan tabel 1 diketahui didapat 38 responden yang diberikan intervensi terapi audio dzikir dalam tabel pre-test untuk tidak nyeri yaitu nyeri sedang 32 respoden $(84,2 \%)$, nyeri berat 6 responden $(15.8 \%)$, sedangan pada hasil data post-test pemberian terapi audio terapi dzikir yaitu untuk nyeri ringan 12 responden $(31, \%)$, nyeri sedang 22 responden $(57,9 \%)$, nyeri berat 4 reponden $(10,5 \%)$.

Tabel 2. karakteristik diagnosa pemberian intervensi pemberian terapi audio dzikir

\begin{tabular}{lcc}
\hline Variabel & Frekuensi & Persentase \\
\hline BNR & 10 & $26,3 \%$ \\
\hline Hemorid & 2 & $5,3 \%$ \\
\hline Fraktur & 4 & $10,5 \%$ \\
\hline Hernia & 5 & $13,2 \%$ \\
\hline Katarak & 4 & $10,5 \%$ \\
\hline Craniotomy & 1 & $2,6 \%$ \\
\hline Tonsilitis & 4 & $10,5 \%$ \\
\hline Gangren & 2 & $5,3 \%$ \\
\hline HNP & 1 & $2,6 \%$ \\
\hline appendecitis & 5 & $13,5 \%$ \\
\hline
\end{tabular}

Sumber data primer, 2020

Berdasarkan tabel 2 diketahui 38 responden diagnosa tertinggi yaitu adalah BNRsebanyak 10 responden $(26,3 \%)$, hernia 5 responden $(13,2 \%)$ appendecitis 5 resonden $(13,2 \%)$, fraktur 4 responden $(10,5 \%)$, katarak 4 responden $(10,5 \%)$, tonsilitis 4 responden (10,5\%), hemoroid 2 responden $(5,3 \%)$, gangren 2 responden $(5,3 \%)$, craniotomy 1 responden $(2,6 \%)$, HNP 1 responden $(2,6 \%)$.

Tabel 3 Karakteristik jenis operasi Variabel Frekuensi Persentase

\begin{tabular}{lcc}
\hline Exsisi & 10 & $26, \%$ \\
\hline Orif & 2 & $5,3 \%$ \\
\hline Aflat & 1 & $2,6 \%$ \\
\hline Appendicitis & 3 & $7,9 \%$ \\
\hline Acce & 4 & $10,5 \%$ \\
\hline Herniotomy & 5 & $13,2 \%$ \\
\hline
\end{tabular}




\begin{tabular}{lcc}
\hline Laparatomy & 2 & $5,3 \%$ \\
\hline Craniotomy & 1 & $2,6 \%$ \\
\hline Tonsilitis & 4 & $10,5 \%$ \\
\hline Depridemnet & 2 & $5,2 \%$ \\
\hline Amputatum & 1 & $2,6 \%$ \\
\hline Hemoroidextomy & 2 & $5,3 \%$ \\
\hline Laminectomy & 1 & $2,6 \%$ \\
\hline
\end{tabular}

Sumber data primer, 2020

Berdasarkan tabel 3 diketahui 38 responden jenis operasi tertinggi yaitu adalah exsisi sebanyak 10 responden (26,3\%), herniotomy 5 responden $(15,2 \%)$, Ecce 4 responden $(10,5 \%)$, tonsilitis 4 responden $(10,5 \%)$, appendictis 3 responden $(7,9 \%)$, orif 2 responden $(5,3 \%)$, laparatomy 2 responden $(5,3 \%)$, depridement 2 responden $(5,3 \%)$, hemoroidectomy 2 responden $(5,3 \%)$, aflat 1 responden $(2,6 \%)$, craniotomy 1responden $(2,6 \%)$, amputatum 1 responden $(2,6 \%)$, laminectomy 1 responden $(2,6 \%)$.

Tabel 4 Karakteristik jenis anastesi

\begin{tabular}{lcc}
\hline \multicolumn{1}{c}{ Variabe } & Frekuensi & Persentase \\
\hline General & 25 & $65,8 \%$ \\
\hline Lokal & 4 & $10,5 \%$ \\
\hline Spinal & 9 & $23,7 \%$ \\
\hline
\end{tabular}

Sumber data primer, 2020

Berdasarkan tabel 4 diketahui 38 responden jenis anastesi tertinggi yaitu adalah anastesi general 25 responden $(65,8 \%)$, spinal 9 responden $(23,7 \%)$, lokal 4 responden $(10,5 \%)$

Tabel 5 Karakteristik jenis obat nyeri

\begin{tabular}{lcr}
\hline \multicolumn{1}{c}{ Variabel } & Frekuensi & Persentase \\
\hline Ketorolac & 17 & $44,7 \%$ \\
\hline Santagesic & 17 & $44,7 \%$ \\
\hline $\begin{array}{l}\text { Asam } \\
\text { mafenamat }\end{array}$ & 4 & $10,5 \%$ \\
\hline
\end{tabular}

Sumber data primer, 2020

Berdasarkan tabel 4.4 diketahui 38 responden jenis obat nyeri tertinggi yaitu adalah Ketorolac 17 responden $(44,7 \%)$, santagesic 17 responden $(44,7 \%)$, asammafenamat 4 responden $(10,5 \%)$

Analisa uji bivariat

Setelah didapatkan data, selanjutnya dilakukan uji normalitas data terlebih dahulu dengan responden sebanyak 38, sehingga dilihat pada tabel shapiro wilk yaitu 0,008 < 0,05 yang berarti data berdistribusi tidak normal. Maka uji bivariat menggunakan uji non parametrik test yaitu uji Wilcoxon.

Tabel 1Distribusi rata-rata tingkat nyeri pre dan post pemberian intervensi terapi audio dzikir dalam menurunakan nyeri post operasi

\begin{tabular}{cccccc}
$\begin{array}{c}\text { Kelomp } \\
\text { ok } \\
\text { interven } \\
\text { si }\end{array}$ & N & $\begin{array}{c}\text { Mea } \\
\mathbf{n}\end{array}$ & $\begin{array}{c}\text { Media } \\
\mathbf{n}\end{array}$ & $\begin{array}{c}\text { Mi } \\
\mathbf{n}\end{array}$ & $\begin{array}{c}\text { Ma } \\
\mathbf{x}\end{array}$ \\
\hline Pre test & 3 & 2.16 & 2.00 & 2 & 3 \\
& 8 & & & & \\
\hline Post test & 3 & 1.79 & 2.00 & 1 & 3 \\
& 8 & & & & \\
\hline
\end{tabular}

Tabel 1 di atas menunjukan bahwa rata-rata (mean) hasil dari pre test sebelum diberikan intervensi terapi audio dzikir adalah 2.16 sedangkan rata-rata median sebelum diberikan intervensi terapi audio dzikir adalah 2.00 dan pada pre test nilai minimum skala nyeri 2 dan maksimal 3.

Berdasarkan tabel 1 dapat dilihat bahwa rata-rata (mean) hasil dari post test sesudah diberikan intervensi terapi audio dzikir adalah 1.79 sedangkan rata-rata median sesudah diberikan intervensi dalam yaitu 2.00 dan pada post test nilai minimum 1 dan maksimal 3.

Tabel 2 Hasil uji wilcoxon pre-test dan post-test

\begin{tabular}{ccccc}
\hline $\begin{array}{c}\text { Kelompok } \\
\text { intervensi }\end{array}$ & $\mathbf{N}$ & Median & $\begin{array}{c}\text { Mean } \\
\text { rank }\end{array}$ & $\begin{array}{c}\mathbf{P} \\
\text { value }\end{array}$ \\
\hline Pre test & 38 & 5.00 & 8.50 & 0.000 \\
\hline Post test & 4.00 & & \\
\hline
\end{tabular}

*P value $<0.05$ based on Wilcoxon

Dari data diatas didapatkan hasil yang menunjukan peringkat rata-rata pada hasil nilai kelompok intevensi pre-test. Dari uji wilcoxon diatas yang menunjukan

$P$-value sebesar $0.000<0.05$ yang berarti menunjukan adanya pengaruh 
pemberian audio terapi dzikir dalam menurunkan nyeri pada pasien post operasi.

Pemberian terapi audio dzikir dalam menurunkan nyeri luka post operasi yang dirasakan individu. Selain tujuan tersebut terdapat beberapa tujuan lain diantaranya dzikir dapat memberikan ketenangan jiwa dan terlindung dari bahaya dan godaan setan.

Menurut penelitian ini sejalan dengan penelitian Rochmawati (2018). Hasil penelitian ini menujukan dari 40 responden sebelum dilakukan terapi murottal qur'an dengan besar nyeri sedang 24 responden $(60,0 \%)$ dan sudah dilakukan terapi murottl qur'an nyeri ringan 24 reponden $(60,0 \%)$. Hasil uji statistik dari $U j i$ diperoleh nilai $\mathrm{p}=0,000$ jika $\alpha=0.05$ maka $\mathrm{p}<\alpha H_{1}$ diterima. Ada pengaruh murottal qur'an terhadap nyeri pos ops di paviliun asoka RSUD Jombang 2018. Terapi non farmakologi bagi kaum muslim, karena mendengarkan bacaan ayat suci Al-qur'an bisa menurunkan intensitas nyeri pada pasien post ops.

Bedasarkan hasil penelitian dan pembahasan diatas peneliti berpendapat bahwa memberikan terapi audio dzikir dapat menurunkan nyeri post operasi.

Terapi dzikir adalah jenis terapi dengan ritme yang teratur disertai sikap pasrah kepada objek transendensi yaitu Allah. Frase yang digunakan dapat berupa nama-nama Allah, atau kata yang memiliki makna menenangkan sehingga mampu untuk menurunkan nyeri.

Pengaruh membaca dan mendengarkan ayat suci al-quran adalah impus atau rangsangan suara akan diterima oleh daun telinga pembacaanya, kemudian telinga mulai proses mendengarkan. Secara fisiolagi mendengarkan adalah proses dimana telinga informasi kesusunan saraf pusat. Seperti bunyi dihasilan oleh sumber bunyi akan diterima oleh telinga. Getaran tersebut akan diubah menjadi implus mekanik ditelinga tengah dan diubah menjadi implus elektrik ditelinga dalam dan diteruskan memalui saraf pendengran menuju ke korteks batang otak (Rochawati, 2018).

\section{KESIMPULAN}

Berdasarkan hasil penelitian pre-test dan post test terapi audio dzikir dalam menurunkan nyeri post operasi didapat hasil tes non-parametrik dengan uji wilxocon terdapat hasil penurunan nyeri sebelum dan sesudah terapi audio dzikir yaitu $0.008<0.05$.

\section{SARAN}

Diharapkan agar dapat meneliti variabel lain yang lebih bervariasi dan mencakup penelitian yang lebih luas dengan metode penelitian yang bebeda terutama yang berhubungan dengan nyeri post operasi sebelum dan sesudah diberikan intervensi terapi audio dzikir. Sehingga penelitian tentang nyeri sebelum dan setelah dapat terus dikembangkan.

\section{UCAPAN TERIMA KASIH}

Tidak lupa saya bersyukur kepada allah SWT dan mengucapkan terima kasih kepada dosen pembimbing, orang tua dan rekan-rekan yang terlibat dalam penelitian ini sehingga saya dapat menyelesaikan penelitian ini tapat waktu.

\section{DAFTAR PUSTAKA}

Kementrian Kesehatan Republik Indonesia. 2018. Manajemen Nyeri

http://yankes.kemkes.go.id/read-manajemennyeri-4944.html

Mathroni, 2009. Amalan dan do'a Mustajab. Semarang : Aneka Ilmu

Asmadi, 2009. Konsep dan aplikasi kebutuhan dasar klien. Jakarta : Salemba Medika

Notoatmodjo, Soekidjo. 2010. Metodelogi penelitian kesehatan. Jakarta: Rineka cipta

Al-Bughury, Subki, 2010. Dasyatnya ibadah malam. Jarkarta : Qultum Medika

Akrom, Muhammad, 2010. Zikir obat hati. Yogyakarta : Mutiara medica 
Basri, Muh. Mu'inudinillah, 2014. 24 Jam Dzikir \& do'a Rasulullah SAW. Surakarta : Biladi

Mubarak, Iqbal, dkk. 2015. Buku ajaran ilmu keperawatan dasar jilid 2. Jakarta: Salemba Medika

Zakiyah, Ana. 2015. Konsep dan Penatalaksanaan dalam Praktik Keperawatan Basis bukti. Jakarta: Salemba Medika.

Saleh, Arman Yurisaldi. 2018. Berdzikir untuk kesehatan syaraf. Hikura Publising

Ajhari, Abdul Aziz, dkk. 2019. Jalan menggapai ridho ilahi. Bandung : Bahasa dan

Sastra Arab

Budiyanto, Tony, 2015. Pengaruh terapi dzikir terhadap intensitas nyeri pada pasien post operasi CA Mammae di RSUD Prof DR Margono Soekarjo Purwokerto. Jurnal Keperawatan Vol 3. No 2

Darajatun, laila. 2017. Gambaran Penggunaan Analgetika Pada Pasien Pasca Bedah di Rungan III dan Melat i Lantai 4 RSUD DR.Soekardjo Tasikmalaya. Jurnal Fitofarmaka Vol 7. No 1

Munif, Abdul. 2017. Pengaruh pendampingan layanan spiritual do'a dan tawakkal terhadap tingkat kecemasan pre operasi clouse fraktur di rumah Sakit Muhammadiyah Lamongan. Jurnal Kesehatan

Rahmayati, El, dkk .2017. Faktor-faktor yang berhubungan dengan lama perawatan pasien post operasi di Ruang rawat inap bedah rumah sakit. Jurnal keperawatan. Vol 08 . No 2
Marliyana, 2018. Pemberian terapi murottal al-quran terhadap nyeri saat perawatan luka post operasi laparatomi di Rungan Kutilang RS.Dr H.Abdul Moeloek Provisi Lampung. Jurnal Kesehatan Vol 1. No 2

Putri, Wulandari, dkk. 2018. Aroma Terapi Chamomile Menurunkaan Skala Nyeri Pada Ibu Yang Mengalami Luka Episiotomi Dipraktik Mandiri Bidan Ponirah Mojokerto Metro Selatan. Jurnal Keperawatan. Vol 6. No 2

Rohim, Auliaur, dkk. 2018. Pengaruh terapi dzikir kalimat istigfar terhadap skala nyeri pasien post operasi fraktur ektremitas bawah di RSUD Dr.Moewardi. Jurnal Keperawatan.

Wulandari, Putri, dkk. 2018. Efektifitas terapi asmaul husna terhadap penurunan skala nyeri pada pasien fraktur di RSUD Provinsi Riau. Jurnal Endurance

Yadi, Rahmat, dkk. 2018. Pengaruh terapi distraksi visual dengan media vistual reality intensitas nyeri pasien post operasi laparatomi. Jurnal ilmiah keperawatan sai betik. Volume 14. No 2

Barus, Mardiati, 2018. Pengaruh progressive muscle relaxation terhadap tingkat kecemasan pre operasi di rumah sakit santa elisabet medan. Jurnal Keperawatan Vol 1. No 2

Aliasan, 2019. pengaruh dzikir terhadap psikolgis muslim. Jurnal Kesehatan.

Vol. 2 No. 1

Arif, Muhammad, dkk. 2019. Efektifitas terapi musik mozart terhadap penurunan intensitas nyeri pasien post operasi fraktur. Jurnal Kesehatan medika saintika. Vol 10. No 1

Himawan, Riska, dkk. 2019. Pengaruh terapi dzikir terhadap tingkat nyeri pada 
pasien post operasi benigna prostat hyperplasia di RSUD RA. KARTINI Jepara. Jurnal Keperawatan dan Kebidanan Vol.10. No 1

Redho, Ahmad, dkk. 2019. Pengaruh self healing terhadap penurunan sskala nyeri pasien post operasi. Jurnal Keperawatan dan Kebidanan. Vol 1. No 1

Cahyani, 2018. Pengaruh terapi relaksasi dzikir dan terapi dzikir murottal alqur'an terhadap penurunan tekanan darah pada pra lansia penderita hipertensi. Universitas Islam Negeri Uin Alauddin.

Rochmawati, Nanik. 2018. Pengaruh murottal al-quran terhadap nyeri post operasi. Sekolah Tinggi Ilmu Kesehatan Insani Cendikia Medika.

Rumah Sakit TK II Dr. AK Gani Palembang, 2019. Data pasien operasi. 